\title{
O OFÍCIO DE BENZER COMO PRODUÇÃO DE CONHECIMENTO NO MUNICÍPIO DE TRACUATEUA - PA - AMAZÔNIA - BRASIL
}

\author{
Rita Cassia de Quadros Castro ${ }^{1}$ \\ Gisela Macambira Villacorta ${ }^{2}$
}

\begin{abstract}
RESUMO
O ofício de benzer consiste em uma prática cultural do saber popular do Município de Tracuateua/PA relacionada à cura religiosa. Além dos seus aspectos espirituais intrínsecos, o benzimento é uma importante fonte de produção de conhecimento daquela comunidade, em que pese à desvalorização de sua prática em relação ao saber científico. Pensando nessa temática, este trabalho objetivou, mediante estudo etnográfico, analisar a epistemologia da benzeção, a partir do saber popular e de práticas de cura, partindo do conceito da educação da atenção proposto por Tim Ingold. Busca-se relatar os impactos da sobreposição do saber científico sobre outros saberes, identificar as razões da desvalorização das práticas de benzimento e sinalizar a importância de diálogos entre saberes e da valorização do conhecimento, independentemente de sua origem. A partir desta análise epistemológica, almeja-se subsidiar políticas públicas para a valorização dos saberes e das práticas culturais.
\end{abstract}

Palavras-chave: Benzeção, Etnografia. Tracuateua.

\section{BLESSING AS KNOWLEGDE PRODUCION: ETHNOGRAPHYING BLESSING PRACTICES IN TRACUATEUA - PARÁ - AMAZON - BRAZIL}

\begin{abstract}
The craft of blessing consists of a cultural practice of popular knowledge in the Municipality of Tracuateua/ PA related to religious healing. Besides its intrinsic spiritual aspects, blessing is an important source of knowledge production for that community, despite the devaluation of its practice in relation to scientific knowledge. On regard to this theme, this work aimed, through an ethnographic study, to analyze the epistemology of blessing, from popular knowledge and healing practices, based on the concept of education of attention proposed by Tim Ingold. We seek to report the impacts of the overlapping of scientific knowledge over other knowledge, to identify the reasons for the devaluation of blessing practices and to signal the importance of dialogues between knowledges and the valorization of knowledge, regardless of its origin. From this epistemological analysis, we aim to subsidize public policies for the valorization of knowledge and cultural practices.
\end{abstract}

Keywords: Blessing. Ethnography. Tracuateua.

Data da submissão 14.10 .2020

Data da aprovação 14. 12. 2020

\section{INTRODUÇÃO}

Sou professora da comunidade do Cocal, interior de Tracuateua, situada no nordeste paraense, localizada na zona rural do município, na região de campos naturais, sou professora

\footnotetext{
${ }^{1}$ Possui graduação em Licenciatura Plena em Letras pela Universidade Federal do Pará (2008). Possui Gestão Escolar, pela Escola de Governo do Pará - EGPA. Especialista em Educação para Relações étnicos raciais, pelo Instituto Federal de Educação Tecnológica do Pará - IFPA. Mestra em Estudos Antrópicos da Amazônia, pela Universidade Federal do Pará, campus de Castanhal. E-mail: cassiakuadros@yahoo.com.br

2 Possui graduação em Ciências Sociais pela Universidade Federal do Pará (1996) e mestrado em Antropologia pela Universidade Federal do Pará (2000). Doutora em Ciências Sociais com concentração em Antropologia (intercâmbio na UFRGS-Antropologia).
} 
há vinte anos e mãe há cinco. Tracuateua se tornou um município recentemente, tendo apenas vinte e quatro anos de emancipação do município de Bragança/PA, que fica a aproximadamente $200 \mathrm{~km}$ da capital Belém/PA e possui cerca de 30 mil habitantes, segundo o último censo demográfico (IBGE, 2019).

Minhas perguntas surgiram após um contato com uma benzedeira, que inicialmente aconteceu sem qualquer objetivo acadêmico. Em 2015, após a chegada de meu primeiro filho, tudo mudou, a casa mudou, os amigos mudaram, os programas em famílias mudaram e tanta transformação foi por conta de um novo ser que passou a integrar a família. O leitor poderia indagar: qual o sentido de eu narrar aqui a chegada de uma criança na família com a pesquisa que aqui estou apresentando?

Neste sentido, em uma determinada manhã, já com três meses de vida, meu filho começou a ter febre alta logo cedo, às 6h da manhã, acompanhada de calafrios e choro. Pensei que poderia ser uma das viroses típicas do inverno amazônico; assim, como é de praxe, levei meu filho ao pediatra. O pediatra receitou antitérmico e vitaminas. Porém, após a febre ceder, apareceu outro sintoma - diarreia -, com fezes um pouco "esverdeadas", o que chamou a atenção da avó. Embora a cor das fezes chamasse atenção, o cheiro não era característico de algum tipo de infecção alimentar. Mesmo assim, fiquei atenta ao sintoma manifestado.

Já seguíamos para o terceiro dia e meu filho não apresentava melhoras. Mesmo quando os sintomas abrandavam, eles retornavam pontualmente às $6 \mathrm{~h}, 12 \mathrm{~h}, 18 \mathrm{~h}$ e $00 \mathrm{~h}$. E foi essa pontualidade sintomática que fez com que a segunda mãe de meu filho concordasse comigo e com a avó em sair para pedir ajuda a uma benzedeira.

Fomos então à casa da Sra. T., benzedeira. Sugeri a ida especificamente até a casa dela porque já a conhecia há muito tempo e já tive sua ajuda outras vezes, pois desde minha infância convivo com benzedeiras, parteiras e experientes; inclusive, na minha casa, todos nós, exceto minha irmã caçula, nascemos com o auxílio de parteira, carinhosamente chamada de "vovó Mercedes", que também era benzedeira.

No final da tarde fomos à casa da dona T.. Meu filho ainda chorava e estava com muita febre. Ao chegarmos lá, pedi para falar com dona T., que estava cuidando da neta. Ela nos deu cadeiras para nos acomodar e eu contei todo o ocorrido. Ela então pediu para tirar toda a roupa dele, entrou na casa, retornou com um alho na mão e começou a rezar e benzer o meu filho com o alho. Ela passava o alho no corpo dele e ao mesmo tempo fazia orações. Neste momento, fazia um vento muito forte.

Lucas, meu filho, chorava enquanto ela fazia o sinal da cruz nele e o abençoou. Após benzê-lo, ela disse que ele ficaria bom logo que voltasse para casa, que o problema havia sido quebranto e ele havia sido admirado por uma mulher, e ela estava grávida. Voltamos para casa, Lucas chegou suado, sem febre. Esperamos chegar 18 horas para ver se a febre voltava, mas não voltou. Meia noite também a febre não apareceu, assim como os outros sintomas. Assim, felizmente, meu filho logo estava bem.

Neste momento, este estudo buscará se clarificar, mesmo com a complexidade do método etnográfico, complexo no sentido de sua relação essencial e interdisciplinar com diversas áreas (antropológica, filosófica, biológica etc.), sendo capaz de construir algo de forma que cada uma das áreas citadas possa renovar ou enriquecer suas formas de apreensão da realidade acerca do assunto estudado.

Estou considerando que as benzedeiras e os benzedores em seu ofício mantêm uma relação fenomenológica com o mundo. Neste sentido, faço um paralelo com Tim Ingold (2015) ao tratar sobre os elementos não humanos, que estão também no mundo interagindo com os humanos, a exemplo dos materiais que são feitos os objetos e produzem uma materialidade.

As plantas também são matérias, ainda que não produzam objetos, fazendo parte do arsenal que compõem a prática da benzeção, apreendida cotidianamente a partir de experiências deixadas por outras gerações, e ganha uma habilidade mais específica no presente. 
As orações e as rezas procuram buscar a necessidade de instrumentos, através de objetos que se utilizam durante as benzeções e dependem de cada benzedor. Os instrumentos incluem: plantas, água, alho, roupas, fotos, terço. Mas normalmente eles em sua maioria utilizam ramos ou galhos para o benzimento.

Tendo em vista este contexto, pretendo analisar nesta pesquisa o ofício de benzer como produção de conhecimento, etnografando práticas de benzeção do município de Tracuateua/PA a partir desta outra forma de saber e de suas práticas de cura.

\section{FUNDAMENTAÇÃO TEÓRICA}

A cidade de Tracuateua pertence à mesorregião do Nordeste do Pará e à microrregião Bragantina, também conhecida como zona do Salgado. O município possui aproximadamente 30.959 habitantes, conforme estimativa do IBGE e densidade populacional de quase 29,39 $\mathrm{hab} / \mathrm{km}^{2}$. (IBGE, [2019]). Segundo informações da Secretaria de Estado de Turismo (2014), Tracuateua fica a aproximadamente $188 \mathrm{~km}$ da capital Belém e a $15 \mathrm{~km}$ do município de Bragança. No estudo em questão, dei prioridade para os locais onde se localizavam benzedores conhecidos pela comunidade, a saber, os povoados de Santa Maria, Tracuá e a Comunidade Quilombola do Jurussaca (Fig. 1).

Figura 1 - Mapa do Município de Tracuateua, com destaque para as comunidades pesquisadas

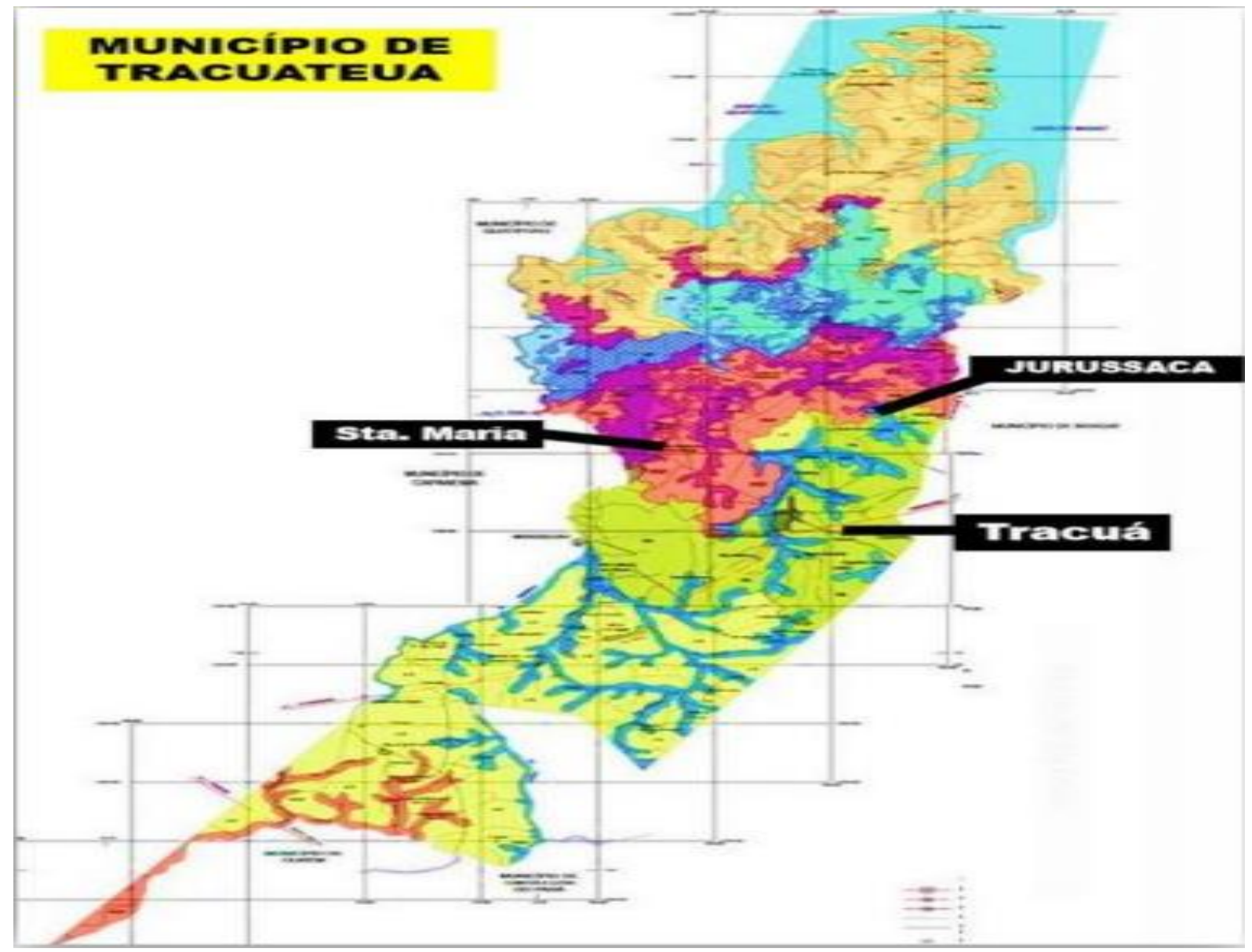

Fonte: elaborado pela Autora.

A comunidade de Santa Maria encontra-se situada na zona rural de Tracuateua. Nesta comunidade vivem aproximadamente 40 famílias, a economia vem da agricultura familiar (produção de grãos, milho, feijão, mandioca), da pesca de subsistência e da criação de animais 
de pequeno porte (galinha, patos, porcos e gado). Possuem 1 (uma) escola de ensino fundamental, 2 (duas) igrejas (católica e evangélica) e 1 uma Unidade Básica de Saúde - UBS. Nesta comunidade, temos a benzedeira Dona T.

Bem próximo da sede do município a cerca de $4 \mathrm{~km}$, temos a comunidade de Cajueiro Grande/Tracuá, embora a proximidade da sede seja tamanha, isso não faz diferença alguma na vida dos que residem na mesma. A comunidade conta apenas com uma escola de ensino fundamental menor, e não possui nenhum serviço básico (posto de saúde, água encanada, coleta de lixo etc.), lá vivem cerca de 20 famílias, que vivem basicamente da agricultura e roças de mandioca. Nesta comunidade temos um benzedor, o Seu S.T.

Por fim, a comunidade Quilombola de Jurussaca abriga atualmente 45 famílias, descendentes de escravos. Segundo depoimento de moradores mais antigos da localidade, os fundadores da comunidade fugiram das fazendas nos arredores de Bragança (REIS; VIEIRA, 2016). Possuem como atividade econômica principal a agricultura familiar de subsistência, criação de pequenos animais e extrativismo. Na comunidade, é muito comum ainda encontrar moradores que detêm conhecimentos sobre plantas medicinais encontradas nas matas nativas, e também moradores que se interessam e conhecem sobre plantas cultivadas em quintais, o que é reforçado pelo benzedor estudado, o Sr. J.C

Conforme Reis e Vieira (2016, p. 4), que estudaram o ritual de beberagem na comunidade de Jurussaca, a história do município "está inserida no circuito que 'abriga' comunidades afrodescendentes e indígenas"”. Seu surgimento está diretamente relacionado à construção da estrada de ferro Belém-Bragança, em 1908, que promoveu o processo de povoamento pela vinda de trabalhadores da região nordeste (REIS; VIEIRA, 2016). Conta-se que o nome Tracuateua veio da referência dos trabalhadores da estrada de ferro, que reclamavam da quantidade de formigas pretas (tracuás) no local (SETUR/PA, 2014).

Historicamente, as mulheres têm se mostrado profissionais com êxito na prática da medicina, seja na alimentação, no asseio, na cura de doenças e também na saúde espiritual daqueles que estão por perto. Não por acaso, pode-se dizer que esta relação entre o feminino na história e os cuidados com o próximo advém do conceito da maternidade e da interdependência humana com a mãe/mulher, tendo se estendido para além da comunidade familiar, fazendo assim com que surgissem as benzedeiras, rezadeiras e conselheiras (MACIEL; GUARIM NETO, 2006).

Ainda no que diz respeito à prática de rituais realizadas no passado, pode-se estabelecer uma diferença importante quanto a participação do homem e da mulher, o que se mantém até hoje se comparamos com as práticas de benzimento feitas pelos benzedores e benzedeiras de Tracuateua. Esses aspectos apresentados acima configuravam um modelo das relações entre homens e mulheres (MOTTA-MAUÉS, VILLACORTTA, 2000).

É importante considerar a diferença que existe entre essa classificação simbólica de homens e mulheres e a sua classificação social, o que implica numa autêntica inversão de papeis ou posições. Enquanto na primeira classificação o homem ocupa uma posição estável e a mulher transita entre domínios, na segunda, a ele é permitido circular e atuar, livre e efetivamente em qualquer domínio de qualquer área do sistema social, ao passo que a mulher são impostos limites rígidos, restringindo-se drasticamente as oportunidades para seu desempenho na sociedade (MOTTA-MAUÉS; VILLACORTTA, 2000).

Vale esclarecer, ainda, o que entendo sobre doenças naturais e não naturais. A doença que acomete o ser humano fisicamente é classificada como natural, o que é explicado por Maués (1990), e as doenças não naturais seriam aquelas causadas além do caráter físico, já chegando ao nível espiritual do ser humano. No entanto, os benzedores de Tracuateua apresentam uma nomenclatura diferente das encontradas em seu trabalho de campo; segundo eles, há doenças que são para médicos e outras para benzedores. 
No mesmo sentido, Boaventura de Souza Santos (2004), em sua teoria crítica pósmoderna, abre espaço para a luta emancipatória e o desafio representado pela articulação entre os saberes científicos, bem como entre outros saberes. Essa discussão epistemológica torna-se fundamental neste estudo, pois nos deparamos frequentemente com o saber hegemônico científico tentando suprimir os demais saberes.

Diante das argumentações de Boaventura, temos a análise das relações entre a prática médica oficial e aos tratamentos populares que apresentam essa divisão: a medicina com o empírico, a farmacopeia, o racional e o orgânico, entre outros; e do lado das práticas populares, encontraríamos o simbólico, o ritual, o mágico, o psicológico, o sagrado e o social.

Não há como ignorar ou deixarmos de relacionar a prática dos benzedores aos pressupostos de Ingold quando faz suas indagações que destacam que desde o simples hábito de tomar um chá para algum tipo de enfermidade receitado por nossos avós ou alguém mais velho, quando continuamos a propagar essas receitas aos nossos filhos, damos prosseguimento a um ritual de conhecimento que sem dúvida contribui a várias gerações.

Foram muitos relatos até chegar aos benzedores, uma vez que há inúmeras pessoas que foram curadas de algumas enfermidades. Isso não é algo recente, as práticas de benzimento fazem parte do cotidiano das pessoas, dos costumes tradicionais e da cultura religiosa também, merecendo ser reconhecidos de algum modo como detentores de saberes e de um trabalho único. $\mathrm{O}$ reconhecimento dos benzedores e de seus saberes populares tradicionais, como o do saber científico, é imprescindível para corroborar a existência de uma epistemologia dos benzedores.

\section{ETNOGRAFANDO AS BENZEDEIRAS E OS BENZEDORES DE TRACUATEUA}

Antes de iniciar o relato de experiência com os Benzedores e Benzedeiras do município de Tracuateua, é imprescindível apresentar as descrições dos métodos utilizados para esta pesquisa e para a coleta do material etnográfico. Conforme Malinowski (1978, p. 22-23):

Na etnografia, o autor é ao mesmo tempo, o seu próprio cronista e historiador; suas
fontes de informação são, indubitavelmente, bastante acessíveis, mas também
extremamente enganosas e complexas, não estão incorporadas a documentos
materiais fixos, mas sim ao comportamento e memória dos seres humanos. Na
etnografia é frequentemente imensa a distância entre a apresentação final dos
resultados da pesquisa e o material bruto de informações coletadas pelo pesquisador.

Sob essa diretriz, inicialmente, Ingold (2015, p. 19) esclarece que:

O objetivo da etnografia é descrever as vidas de outras pessoas além de nós mesmos, com uma precisão e sensibilidade afiada por uma observação detalhada e por uma prolongada experiência em primeira mão.

Em Ingold (2015, p. 385), o conceito apresentado sobre o que é a etnografia significa escrever e falar sobre pessoas, destacando-se a ação de se escrever e sobre quem se irá escrever, o que permite o entendimento acerca do seu próprio conhecimento. No entanto, não é qualquer relato sobre um povo que torna a técnica uma etnografia; ao contrário, é necessário um olhar mais aguçado, artístico. As descrições etnográficas se tornam de certo modo mais uma produção única do que apenas um método científico, sem deixar de ser apresentada com coerência, precisão e realidade (INGOLD, 2015).

Quando se fala que as práticas socioculturais e religiosas de grupos étnicos no Brasil apresentam características próprias de uma história das mentalidades, como afirma Chartier (1991), significa dizer que essas práticas são distintas e coletivas, mas são representadas coletivamente e elevadas a uma só denominação. Nesse sentido, corrobora que os símbolos são 
apresentações do sagrado, sendo uma prática simbólica que resume o ethos de uma comunidade (REIS; VIEIRA, 2016, p. 8). Nesse sentido, Reis e Vieira (2016) corroboram que "seja qual for o discurso ou o meio, a representação do fato é uma referência e assim, temos que nos aproximar dela".

Essa aproximação do sagrado é perceptível nos rituais de prática dos benzedores e benzedeiras, reforçando dessa maneira vários tipos de reflexões acerca das práticas de cura. Conforme Nascimento (2010) e Quintana (1999), na literatura, há pesquisas que evidenciam a constante interlocução dos benzedores com o além, ou seja, com a ordem divina, sagrada.

Estabelecer o diálogo com benzedores foi essencial para construção de todo o método de pesquisa. $\mathrm{O}$ calendário para coleta de dados e visitas in loco foi dividido conforme a disposição dos benzedores e as pessoas atendidas, a cada visita foram fotografadas e feitas anotações em diário de campo; além disso, o termo de consentimento foi apresentado a todos os participantes. Solicita-se que os sujeitos (benzedores e pessoas atendidas por eles), relatem detalhadamente como acontece todo o processo de benzimento, desde as manifestações de doenças, até a cura após o benzimento.

A metodologia e a postura epistemológica sugerida neste estudo científico permite analisar epistemologicamente o ofício dos benzedores, delineando e tecendo um estudo que respeite e corrobore com aquilo que o outro compreende e acredita como certo, a partir do seu próprio saber, o qual está baseado numa cultura e na particularidade de cada pessoa, bem como, descrevendo o ato de benzimento, a sobreposição do saber científico sobre outros saberes, identificando as razões para a desvalorização das práticas de benzimento e meios para sugerir políticas públicas que valorizem esses saberes populares.

Em conversas com pessoas idosas da região, encontramos os benzedores, que chamaremos de Dona T, Sr. J.C e Sr. S.T. Entre os mais conhecidos atualmente estão dona T., que é somente benzedeira, e seu S. T., experiente e benzedor. Ambos residem em áreas rurais do município. Dona T. possui 65 anos e seu S.T., 75 anos. Ambos são católicos. Seu J.C, 59 anos, é benzedor e reside na comunidade quilombola de Jurussaca.

Segundo Maués (1994, p. 76-77), os especialistas locais que tratam de doenças não naturais são o benzedor e o experiente, sendo que ambos possuem métodos específicos no tratamento das doenças. O esclarecimento de Maués é fundamental, pois apresenta os conceitos e as diferenças de algumas palavras utilizadas neste estudo, tais como experientes e benzedores. O experiente lança mão de chás, "leite de paus" (seiva de plantas), "emplastros, banhos, defumações, pomadas, fricções, vomitórios, excrementos de animais, saliva humana e outros" (MAUÉS, 1990, p. 204), bem como remédios de farmácia. Além disso, é fundamental o experiente "dar a sua finesa", isto é, indicar para o paciente o resguardo e as proibições no período de tratamento para que a substância não se torne venenosa no paciente.

As referências sobre os benzedores na região são inúmeras. Dona T. é uma das benzedeiras mais conhecidas na região de campos. Muitas pessoas a procuram, de crianças a idosos, mas principalmente mulheres grávidas. S.T. também é muito procurado, mas seu maior público são crianças. J.C. atende a todos, sem distinção de gênero e faixa etária.

Ambos rezam durante as benzeduras. Rezam orações católicas conhecidas como: Pai nosso, Ave Maria, Santa Maria e Creio em Deus Pai, há também uma oração que permanece em segredo, as fazem silenciosamente, quase inaudíveis. Conforme os benzedores são nestes momentos que ocorrem à cura e algo é sentido apenas por eles.

Segundo Dona T, normalmente os benzedores são procurados para curar as doenças que os médicos não conseguem resolver, mas que para os benzedores são reconhecidas por sintomas pontuais: febre alta, acompanhada de calafrios e choramingo, diarreia, fezes "esverdeadas" e sobressaltos (pequenos sustos), que é característico do que é chamado de quebranto (informação oral, 2018). Isso segue a existência da prática do benzimento, que é uma arte 
intercessora entre os comandos do homem e do reconhecido localmente como sagrado, que é capaz de agir sobre tais aparecimentos.

Quando se fala do ritual terapêutico, podemos citar desde o início da benzeção, onde a pessoa é colocada em um assento (uma cadeira comum), num local onde haja luz, ou em direção da mesma, e assim são feitas as benzeções, com as orações auxiliadas com folhas ou ramos de algumas plantas, ou mesmo com a utilização das mesmas embebidas em álcool etílico.

Ao ser indagados sobre umas características que defina quando a pessoa está aquebrantada, os benzedores relatam que há uma peculiaridade entre os sintomas; todo instante, os olhos permanecem com lágrimas.

Os benzedores de Tracuateua possuem uma rotina como de qualquer outra pessoa; entre o trabalho da casa e da roça, seguem realizando os benzimentos.

Dona T. realiza os trabalhos domésticos e cumpre outras rotinas como a maioria das pessoas, trabalha em casa, cuida dos netos e realiza os benzimentos sempre que solicitada. Ela também produz alguns produtos para tratamentos de tosse, gripe e inflamações, agregado ao dom de benzer realiza cursos sobre plantas medicinais ofertados pela Pastoral da Igreja Católica. Entre esses produtos estão xaropes, garrafadas, chás e extratos.

Seu S.T levanta às $5 \mathrm{~h}$ da manhã todos os dias e sua rotina consiste em cuidar de seu pequeno sítio; isso compreende a limpeza do lugar, o cuidar da roça e das pequenas criações. Os benzimentos acontecem no decorrer do dia, sempre que ele é procurado. Seu S.T também sugere o uso de plantas e xaropes para o tratamento quando é necessário.

O senhor J.C assim como dona T e seu S.T também cuida de seu pequeno sítio, cria animais de pequeno e grande porte, e possui horários reservados para seus trabalhos que consiste em benzimento, rezas, amarrações, orações etc.

Todos os benzedores afirmam que sempre que alguém procura ajuda, eles já sabem o que a pessoa tem, e porque estão lá. E que sempre são avisados "por eles" com antecedência.

Durante a benzeção, é possível perceber que os benzedores se concentram, silenciosos rezam, algumas vezes em voz audível, outras não, e utilizam palavras milagrosas, que não são reveladas. $\mathrm{O}$ que se pode perceber é que o benzimento, para essas pessoas simples detentoras de um conhecimento literalmente poderoso, é o ato de tornar benzido ou sagrado algo a ponto de curar. É o ato de cruzamento, ou seja, simbolicamente fazer o sinal da cruz diante de alguém, algo ou local e realizar uma espécie de operação do objeto ou sujeito a ser benzido e curado.

Embora seja reconhecido, o saber popular dos benzedores não é levado em consideração pela medicina convencional. A maioria dos pacientes dos benzedores enfrentam resistência quando relatam aos profissionais médicos que fazem tratamento paralelo junto aos benzedores.

O benzedor da comunidade do Cajueiro Grande não é tão detalhista quanto Dona T. Numa segunda-feira, em minhas observações em campo, ele recebeu um garotinho em sua casa, a mãe já havia lhe procurado fazia alguns dias. Ela apareceu bem cedo, antes das $7 \mathrm{~h}$ da manhã, mas seu S.T. já estava acordado há bastante tempo. Ele foi até o quintal, pegou uma folha bem vistosa de peão-roxo (Jatropha gossypiifolia), e trouxe na mão.

Ouviu atentamente o relato da mãe e logo em seguida sentou a criança meio chorosa em uma cadeira. Ele rezou baixinho, fez orações, pegou a folha de peão-roxo e passou pela cabeça e corpo do garotinho. Após benzer a criança, seu S.T. disse à mãe que o garoto era "gaiato", muito falador e chamava muita atenção dos outros, por isso era fácil de "pegar" quebranto. Ao terminar de benzer a criança, a folha de pião-roxo estava completamente murcha e a criança mais saudável do que nunca.

Aqueles que possuem informações mais especializadas sobre o cultivo e a utilização das plantas, de ervas e suas formas de cura e para tratamento e que podiam colocar em prática os benzimentos ou as simpatias eram conhecidas ou identificadas como benzedores e benzedeiras. Atualmente, apesar das inúmeras dificuldades por quais passam, possuem de certo modo um 
prestígio junto às suas comunidades, sendo respeitados pelos seus serviços à saúde do povo de determinado lugar.

Para a produção de chás é necessário a identificação do problema por qual a pessoa está acometida. Em alguns casos de problemas gastrointestinais (dores de barriga ou cólicas abdominais), são utilizadas folhas secas ou verdes, que são fervidas em pequenas quantidades com água e depois de coadas são definidas para utilização em horários determinados.

Figura 2 - Benzimento utilizando "Pião - roxo"

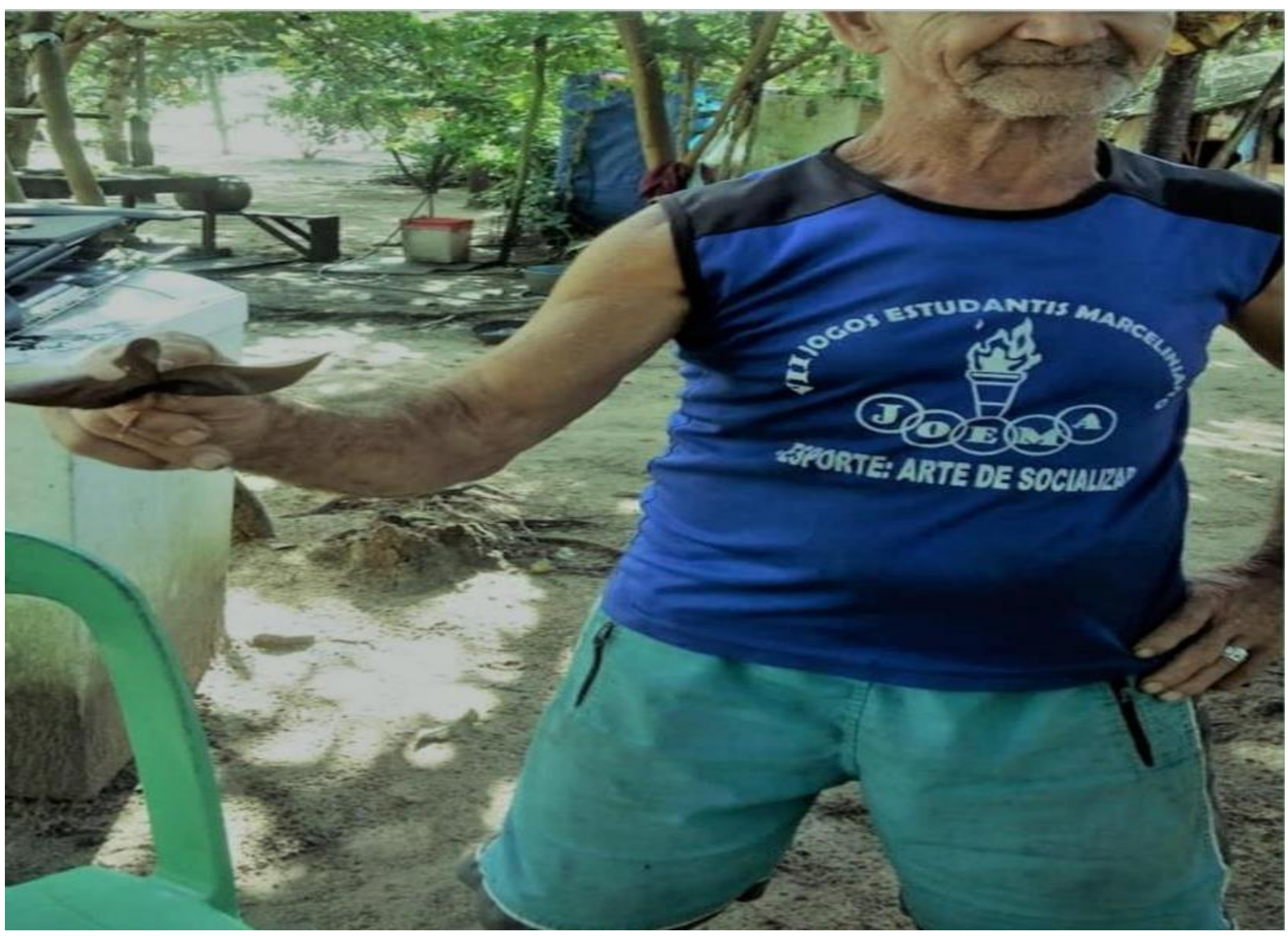

Fonte - Acervo da autora.

Os xaropes na maioria das vezes são utilizados com as partes das plantas, açúcar ou mel, isto somente quando o paciente pode utilizá-los. Normalmente as folhas são cozidas junto com mel ou açúcar e depois armazenadas em pequenos potes ou frascos de vidros para consumo e tratamento.

As garrafadas são feitas com partes das plantas, cascas, entre outras ervas. Ficam armazenadas em garrafas até adquirirem o ponto de consumo, sendo que existem garrafadas para cada doença específica, seja gastrite, inflamações femininas, sendo estas as mais conhecidas, por estar relacionadas à saúde feminina (VALE, 2018, p. 3).

Dentre as similaridades observadas entre os benzedores e benzedeiras participantes deste estudo, podemos ainda destacar: a) o saber advindo de seus antepassados e melhorados com as vivências do dia a dia de cada benzedor e de cada benzedeira; b) a forte demonstração de fé nas suas crenças religiosas e símbolos; c) o vasto conhecimento sobre as plantas e suas propriedades, além da prática de produção de remédios a partir dessas plantas, bem como da sabedoria popular. Segundo Ben (2015), normalmente os benzedores são pessoas já em idade avançada, experientes, alguns sem instrução formal, mas com um conhecimento amplo, prático e empírico espetacular, demonstrando enfim uma grande preocupação com a transmissão e 
continuidade de suas informações, uma vez que não possuem a quem ensinar seus conhecimentos.

Com base nos relatos de experiência, diário de campo e registros foi possível produzir um fluxograma para cada benzedor e benzedeira desta pesquisa. O fluxograma é uma ferramenta da qualidade utilizada para representar a sequência e interação das atividades do processo por meio de símbolos gráficos. Os símbolos proporcionam uma melhor visualização do funcionamento do processo, ajudando no seu entendimento e tornando a descrição do processo mais visual e intuitiva. (PEINADO; GRAEML, 2007). O objetivo dos fluxogramas é demonstrar como o ato de benzer acontece e como são utilizados por cada benzedor.

Figura 3 - Fluxograma de práticas de benzeção da Dona T.

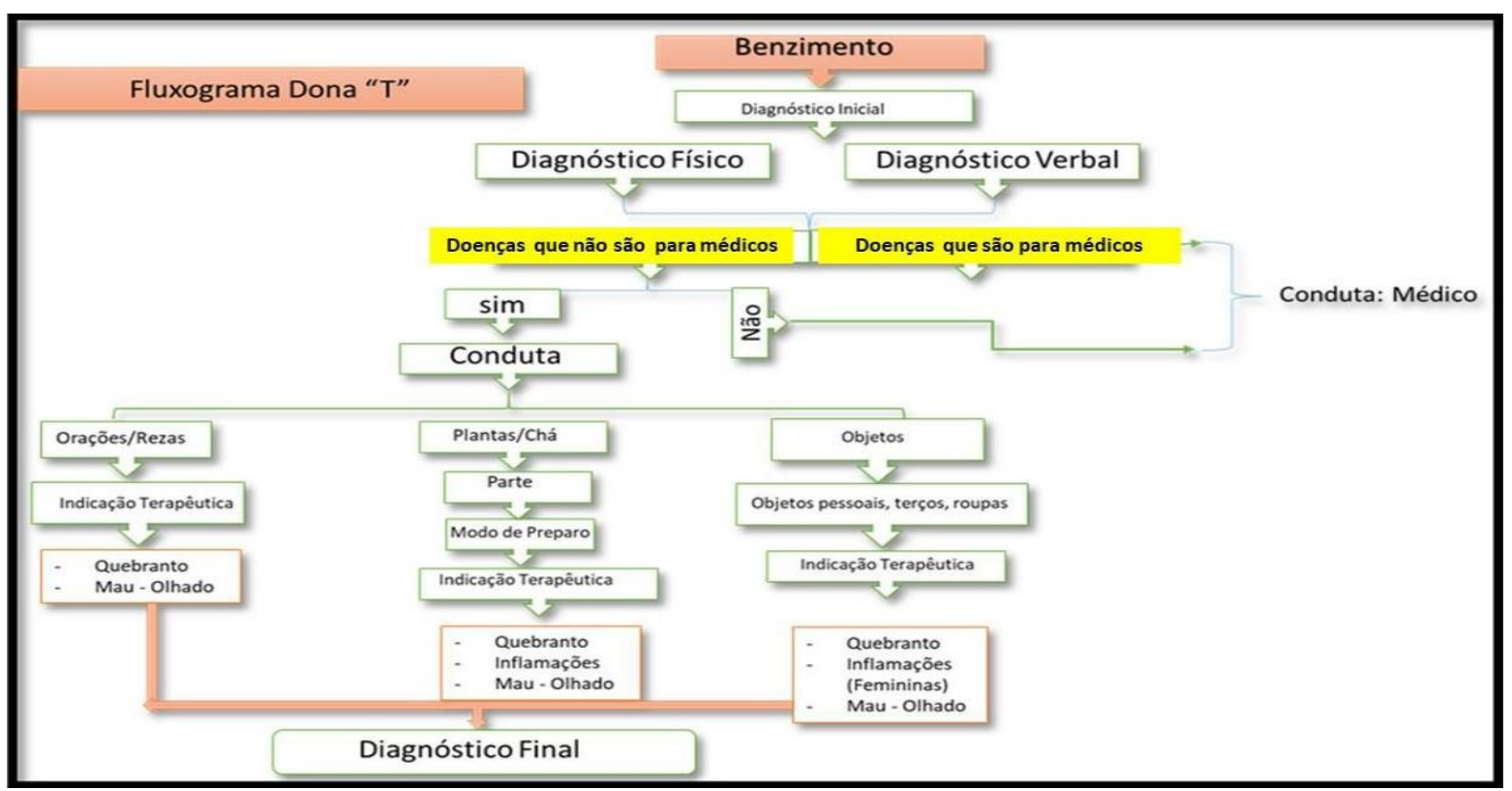

Fonte: elaborado pela Autora.

Dona T. (Fig. 2) inicia o processo de benzimento a partir dos diagnósticos: Físico e Verbal. A partir deles, ela identifica se o paciente sofre de uma doença que pode ser facilmente identificada pelos médicos ou que seja somente identificada através de benzimentos. Dependendo da identificação afirmativa ou não, há um tipo de encaminhamento.

Normalmente, para que Dona $\mathrm{T}$ consiga fazer esse diagnóstico, ela ouve o relato do paciente ou do responsável por ele (a mãe ou pai, quando se trata de crianças). Se a doença for de ordem médica, a conduta é indicação ao tratamento convencional. Se o diagnóstico for de doença onde o benzimento é necessário, dona T. realiza, conforme a necessidade, condutas distintas. Essas condutas são utilizadas conforme a especificidade da doença identificada, podendo ser orações/rezas, plantas/chá e objetos.

No caso de orações/rezas, são indicadas em caso de quebranto ou mau-olhado. As plantas/chá apresentam uma maior especificidade, pois cada parte da planta é utilizada para determinado caso, assim como seu modo de preparo e sua indicação terapêutica, seja para quebranto, inflamações e mau-olhado. Com o uso de objetos, dona T. os utiliza quando o paciente não pode chegar até ela. Nesse caso, ela utiliza objetos pessoais, roupas, terços etc. para realização do benzimento e para o fim específico que poderá ser quebranto, mau-olhado ou inflamações (femininas).

Somente após o emprego das indicações terapêuticas, Dona T. finaliza o seu diagnóstico identificando o tipo de doença não natural. A benzedeira não cobra nem um tipo de valor ou gratificação ao paciente. 
Figura 4 - Fluxograma de práticas de benzeção do Sr. S. T.

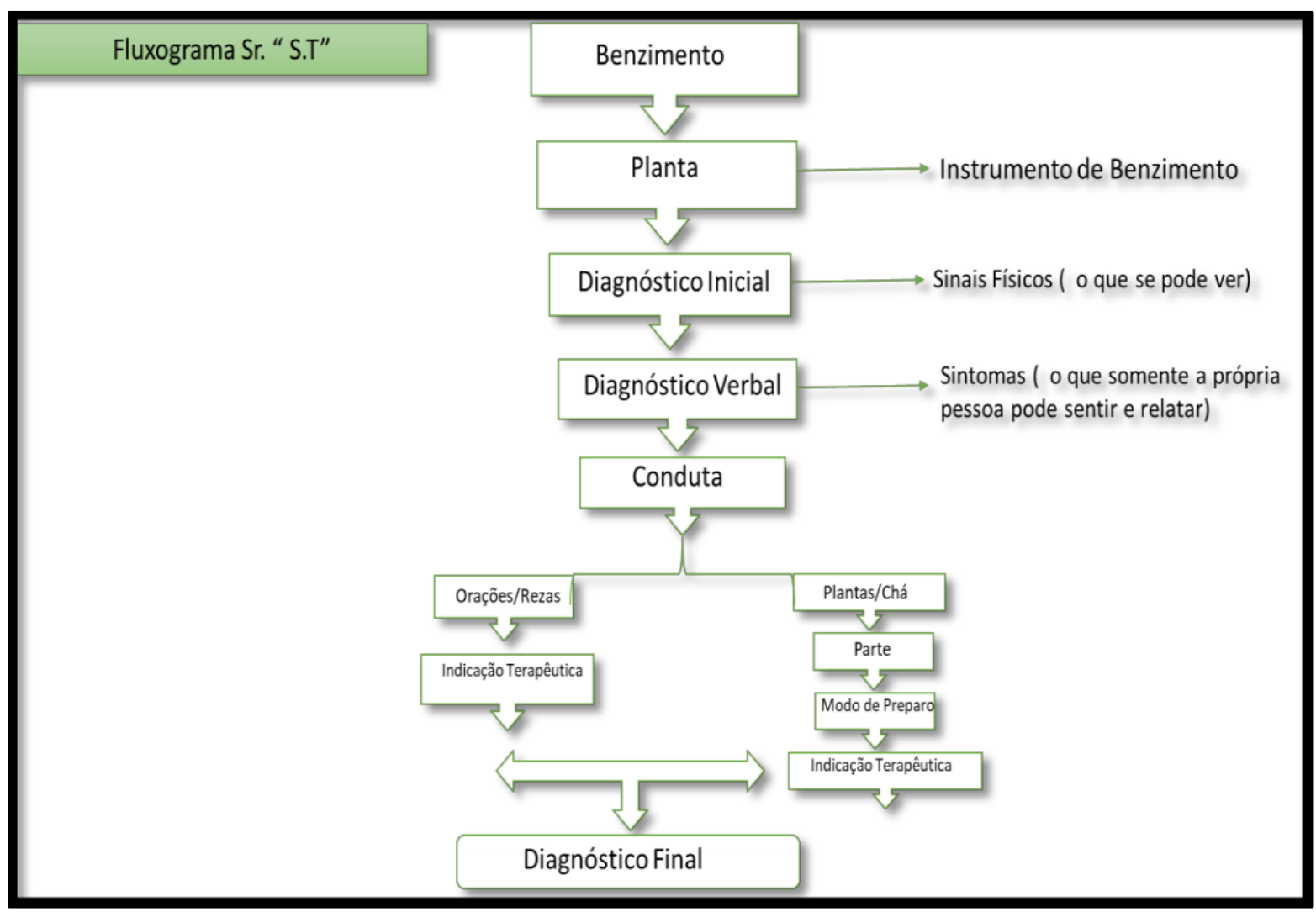

Fonte: elaborado pela Autora.

Para o processo de benzimento, o Sr. S.T. (Fig. 3) é bem mais objetivo. Seu instrumento de benzimento rotineiramente inicia-se com uma planta (Pião-Roxo), que segundo ele, é bastante forte para o diagnóstico inicial, pois a planta murcha dependendo do problema apresentado. O diagnóstico inicial para ele consiste em sinais físicos que qualquer pessoa poderá ver no paciente. Posteriormente o Sr. S.T realiza o diagnóstico verbal que se dá a partir do relato do paciente sobre aquilo que somente ele sente e pode relatar.

Após os diagnósticos, é sugerida a conduta que é utilizada conforme a especificidade do problema apresentado pelo paciente. Esse benzedor sempre realiza orações/rezas e utiliza plantas/chá durante a benzeção.

As orações/rezas são indicadas em caso de quebranto ou mau-olhado e as plantas/chá são utilizadas dependendo do caso, assim como seu modo de preparo e sua indicação terapêutica, para quebranto, inflamações e mau-olhado. Somente após o emprego das indicações terapêuticas, o processo de benzimento é finalizado com a identificação do tipo de doença de ordem não natural. $\mathrm{O}$ benzedor não faz qualquer menção a valores financeiros pelos benzimentos. 
Figura 5 - Fluxograma de práticas de benzeção do Sr. J.C.

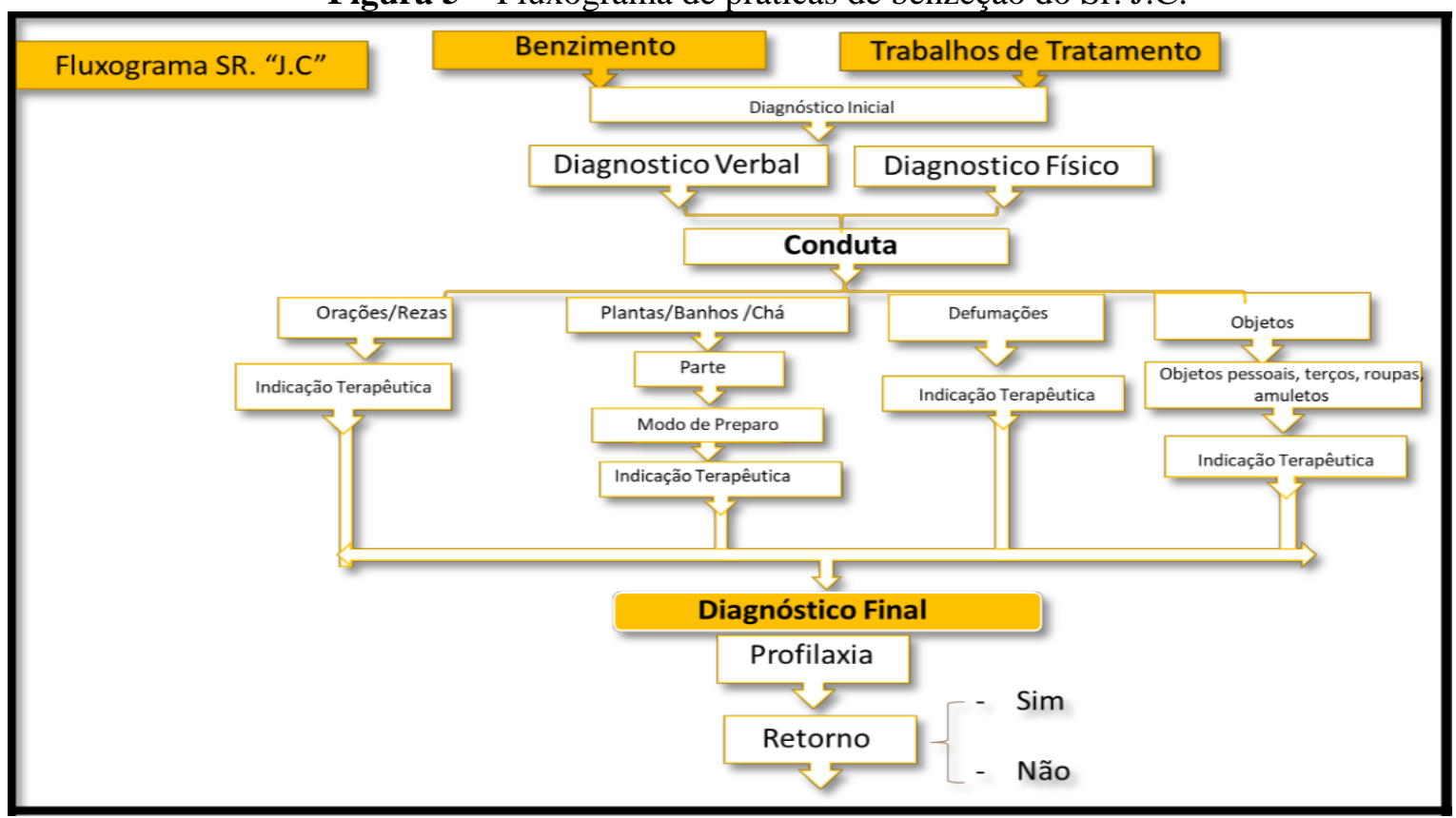

Fonte: elaborado pela Autora.

Para explicação do fluxograma do Sr. J.C. (Fig. 4), há alguns detalhes mais específicos que precisam ser apresentados. Ele realiza benzimentos e trabalhos (espirituais) como tratamento para algumas doenças não naturais, mas somente após identificar a sua necessidade através de um diagnóstico inicial, seguido de diagnóstico físico e verbal. Em seguida, é apresentada a conduta, que consiste em orações/rezas, plantas/chás, defumações e objetos.

As orações/rezas são indicadas por caso, mas em sua maioria são contra quebranto ou mau-olhado e em casos de cunhos espirituais (rituais, trabalhos etc.). Já as plantas/chá são utilizadas dependendo do caso, seu modo de preparo e sua indicação terapêutica, para quebranto, inflamações e mau-olhado. A defumação é utilizada principalmente em trabalhos espirituais, assim como os objetos. Após o emprego das indicações terapêuticas, o benzimento ou o trabalho é finalizado com a identificação do tipo de doença de ordem não natural. Normalmente, como forma de garantia da profilaxia do benzimento ou do trabalho, o Sr. J.C pede que o paciente retorne após alguns dias para o acompanhamento.

O Sr. J.C. é o único entre os benzedores que cobra pelo seu trabalho. Segundo ele, todas as profissões que requerem um tipo de saber cobram por tal conhecimento, sendo injusto ele não receber ou não poder cobrar por algo que ele pratica e possui que é o saber e a prática de cura através do ato de benzer.

A partir do meu primeiro contato com o assunto, conforme observado na introdução, foram sugeridos um planejamento e a descrição da pesquisa, com a apresentação da proposta desta aos sujeitos em questão. A pesquisa bibliográfica e a etnografia sobre os benzedores serão os procedimentos metodológicos neste estudo. É importante discutirmos alguns traços que distinguem a experiência da observação participante e as dificuldades no estudo de algo tão subjetivo, sob as perspectivas do observador e dos observados.

O tempo de ofício de cada participante variou. Dona T., por exemplo, já possui 61 anos como benzedeira, seu S.T. 50 anos, pois iniciou os benzimentos com 20 anos de idade e seu J.C. 52 anos como benzedor, visto que iniciou os benzimentos aos 7 anos após sempre renegálos. Questionados com quem aprenderam a técnica, assim surgiram as respostas: O senhor S.T e J.C. afirmam que aprenderam com Deus, e Dona T., com membros da própria família.

Para chegar aos benzedores de Tracuateua como pesquisadora, as conversas com minha família e com amigos foram fundamentais. Uma de minhas vizinhas relatou que ela também 
benzia, só que "não era tão forte", mas em Santa Maria tinha a Dona T., e ela era "forte". Assim decidi que iria procurá-la em breve e convidá-la para participar da pesquisa.

A chegada ao Sr. S.T. também foi feita através de relatos e testemunhos de várias pessoas dentro da sede do município e na comunidade onde seu S.T. reside. Várias pessoas informaram que havia um benzedor "forte" na comunidade que cuidava muito bem de crianças. Passaram-se três dias para que eu finalmente encontrasse pessoalmente o benzedor.

O terceiro benzedor pesquisado foi seu J.C. da comunidade quilombola do Jurussaca. Este já era por mim bastante conhecido devido aos relatos de meu pai que há muito tempo utilizava de seus benzimentos, em várias situações, mas os relatos das comunidades ao entorno sobre o benzedor me fizeram ir procurá-lo. Curiosamente, ao chegar à residência de seu J.C., ele já sabia da minha ida, mesmo sem qualquer aviso prévio.

Ao chegar à residência de Dona T., era tardezinha, cheguei, bati palmas e pedi para conversar, ela logo pegou algumas cadeiras e começamos uma conversa informal. Ela começou relatando da facilidade e do prazer que sentia em ajudar ao próximo, mas que isso não acontecia dentro da família. Ela não conseguia realizar benzimentos com os familiares, apenas com pessoas desconhecidas. Nesse momento, chegou um casal em uma moto com uma criança, procuravam dona T. para benzer a filha. Ela pediu licença e se retirou. Não pude acompanhála durante este benzimento, pois ainda não havia apresentado meu objetivo ali.

Aproximadamente uma hora após a chegada do casal, Dona T retornou a nossa conversa e começou a falar sobre sua trajetória como benzedeira, desde sua infância até a atualidade, contou sobre as sensações e situações que passava por possuir este dom, relatou também sobre o desaparecimento de um neto que dormia na rede enquanto ela fazia tarefas domésticas, e quando ela foi olhar a criança a mesma não estava mais na rede, quando sentiu sua falta, ela estava bem ao lado de um poço, dormindo. Segundo dona T., quem desejava levar a criança era o Curupira. Isso me fez recordar o quanto ouvi histórias desse tipo na infância.

Dona T. relatou que está disposta para o benzimento sempre que é procurada; ela costumava ir aos domingos à igreja, mas sempre que estava assistindo a missa ela era chamada para auxiliar alguém, e por esta razão ela deixou de ir à missa.

Após os relatos de Dona T., comecei a falar sobre meu interesse pelo seu ofício, e o quanto ele era instigante e necessitava ser estudado, embora a complexidade do assunto seja tamanha. Perguntei sobre a possiblidade de acompanhá-la durante os benzimentos para entender melhor seu trabalho e ela concordou, sugeriu datas e locais para que então eu pudesse começar a pesquisa. A tarde findava e eu pedi licença para retornar no dia sugerido por ela e iniciar as pesquisas em campo.

Em outra manhã de domingo, fui até a residência de seu S.T, cheguei lá por volta das 8h da manhã. Mas seu S.T. acorda muito cedo e já não estava mais em casa a essa hora. Retornei no dia seguinte. Ao chegar à comunidade da Tracuá, seu S.T. já estava de pé. Fui recebida com um abraço e em seguida ele me ofereceu um café. Sua esposa o acompanhava nesse dia. Comecei falando sobre o interesse em pesquisar os benzedores de Tracuateua e disse a ele o quanto havia ouvido seu nome entre as pessoas do município.

Ele então relatou que outros pesquisadores já haviam procurado por ele. E que um deles havia lhe dado um diploma que respaldava seus conhecimentos e que era muito importante para ele. Fiquei curiosa em ver o documento, mas hesitei em pedir a seu S.T. Ele, porém, entrou em sua casa e em seguida surgiu com uma pasta munido de vários papéis. O documento apresentado por seu S.T. era uma declaração de determinado órgão que também realizava pesquisas sobre o trabalho de seu S.T, certificando-o quanto à prática de benzimentos.

Seu S.T. também fez relatos das suas dificuldades, onde se encaixava a família e seus filhos, pois se tornaram fiéis de outras religiões e não gostavam que seu S.T praticasse benzimentos. Mesmo com o impasse, seu S.T concordou em participar da pesquisa, e para não 
atrapalhar sua rotina, pois ele iria para sua roça, combinamos de acompanhá-lo outro dia, já com a permissão garantida.

O encontro com seu J.C. na comunidade Quilombola de Jurussaca, no período da tarde, foi bem interessante. Ao chegar lá, seu J.C. estava sentado embaixo de uma grande mangueira, já esperando a visita. Me apresentei, embora ele já soubesse meu nome. Vale ressaltar que em 2004 trabalhei como professora na comunidade de seu J.C., no entanto, não possui contato com o mesmo. Porém, como ele e meu pai são amigos de longa data, imaginei que por isso ele soubesse meu nome e tivesse achado alguma semelhança entre meu pai e eu. Mas seu J.C. sabia que eu iria visitá-lo naquele dia e sabia meu nome, mesmo sem eu mencionar meu pai.

Ele disse que sabia o porquê que eu estava lá e disse: "Tu pra mim é transparente. Eu te olho e te enxergo de um lado para o outro", por isso eu estou aqui hoje e não sai. Eu sabia que tu vinha (sic) aqui hoje" (informação oral, 2018). Por esse motivo, a conversa com seu J.C foi bem mais direta, falei sobre meu interesse na pesquisa e logo ele se prontificou a contribuir.

Foram feitas visitas às comunidades do município de Tracuateua que possuem benzedores. E na busca da análise epistemológica do ofício dos benzedores no município de Tracuateua - PA, este trabalho foi norteador para a abordagem a utilização da Etnografia.

Para André (2007, p. 105), "o pesquisador que conhece um lugar, a partir do ponto de vista do grupo, dando volume às vozes locais, parte para uma pesquisa do tipo etnográfica". Para que pudesse analisar o ofício dos benzedores no município de Tracuateua/PA, foi preciso estar lá, presenciar, acompanhar o cotidiano dos benzedores, as rezas, os doentes que chegam, e isso só pode ser descrito minuciosamente quando se está presente na realidade. Morar em uma das comunidades que residem os benzedores talvez seja uma das melhores ferramentas de pesquisa.

\section{O SEGREDO DO SAGRADO}

O ofício de benzeção e suas práticas ritualísticas, no conceito de Gomes e Pereira (2004, p. 19), "é uma linguagem oro-gestual com a qual algumas pessoas - detentoras de poder especial - controlam as forças que contrariam a vida harmoniosa do homem. Benzer é garantir o funcionamento da normalidade desejada e conter o mal".

$\mathrm{O}$ processo de benzeção pode apresentar vários sentidos, desde doar o ato de benzer (Eu te abençoo) até admirar-se, espantar-se, passar bons fluídos, produzir os benzimentos, dentre outras nomenclaturas (OLIVEIRA, 1985, p. 8-9). Neste momento; é importante ressaltar que a benzeção, os benzedores, as benzedeiras e seus trabalhos só podem ser compreendidos ao estudar aos fatos que as levaram a iniciar tal prática, isto é, o momento em que recebem o "dom".

Muitas vezes se transmite esse dom entre pessoas de uma mesma família, outras vezes, o indivíduo é identificado como tal por outra pessoa, por possuir uma característica de bondade ou de habilidade para ajudar as pessoas, ou se tem ainda todas essas situações combinadas de diversas maneiras entre si, o que leva a benzedeira a acreditar no seu potencial curativo (OLIVEIRA, 1985, p. 34). Sempre há uma espécie de sinal para a descoberta para a mulher ou o homem escolhido para o dom divino, normalmente relacionado a um episódio muito marcante na vida da pessoa. Segundo Dona T, seu dom foi recebido ainda criança:

Aos 8 anos de idade, na volta para casa, um animal encontrava-se em agonia de parto, minha avó me pediu para pegar o azeite e começamos a benzer juntas, puxava a barriga do animal, até que consegui, e desde aí comecei a benzer (T., informação oral, 2018).

Seu S. T. relatou que chorou no ventre de sua mãe, pois nasceu com o dom, e durante o crescimento sentia que era diferente: 
Existem doenças que não são para os médicos, têm que ser tratadas por nós, benzedores, estou cansado de ir a hospitais para benzer, eles vêm me buscar altas horas da noite para benzer as pessoas, e eu vou. É um dom que DEUS me deu, não posso negar ajuda a ninguém, e não cobro nenhum centavo (S.T., informação oral, 2018).

O saber tradicional tende a se completar, em ambientes diferentes, mediante a relação daqueles que de algum modo carregam consigo este diário. Como exemplo, podemos citar os benzedeiros e benzedeiras, rezadores, erveiros, puxadores (que puxam barriga, costas, um tipo de massagem que alivia dores e outros espasmos musculares), e outros que vão muito além da interação com plantas medicinais.

Em sua maioria, praticam as benzeções no dia a dia através de suas rezas, gestos e energização, mas há aqueles que também complementam seus atos de benzer agregados ao uso de ervas a partir do etnoconhecimento que é componente forte no saber tradicional, assim como a palavra dita aumenta a força do ato ao processo de tratamentos ao doente.

É nesse contexto que devemos entender a naturalidade do sobrenatural para o reestabelecimento da saúde física e mental, uma vez que a noção religiosa de corpo e alma, inseparáveis desde o instante do nascimento, comporta a existência de sintomas físicos oriundos de problemas espirituais, cuja cura exigia o conhecimento de produtos da fauna e da flora com orações e benzeduras (ANZAI, 1985, p. 129).

As benzeções começam a ser rezadas em voz baixa, em murmúrios e muitas às vezes, de forma quase que inaudível ou incompreensiva. O clima de segredo e mágico contribuiu para a preservação e para a variação regional nos textos sobre benzimento, assim como a inclusão de equivalências simbológicas e nativas distintas de região, muito embora venham a manter em sua estrutura o ritual e as rezas, e os elementos invariáveis e corriqueiros embora possuam ter significados distintos.

Referente às orações, Confortin (2005, p. 21) explica que "geralmente são expressas em termos simples, às vezes até mesmo um tanto obscuros e incompreensíveis, mesclam valores do cristianismo, do folclore e das religiões africanas e indígenas".

Por essa razão, muitas doenças tratadas pelas benzedeiras e benzedeiros quilombolas não constam com a mesma nomenclatura da lista de tratamentos da medicina institucionalizada, como mostra a Tabela 1:

Tabela 1 - Doenças identificadas pelos Benzedores e Benzedeiras de Tracuateua

\begin{tabular}{l|c}
\hline \multicolumn{1}{c}{ Doenças } & Características/Sintomas \\
\hline Quebranto & Olhos lacrimejantes; moleza por todo o corpo; tristeza; bocejar constante; \\
espirros repetidos e inapetência.
\end{tabular}

Fogo selvagem

Bolhas e lesões na pele.

Fonte: elaborada pela autora. 
Percebe-se que cada praticante de benzimentos possui seu próprio método de trabalho, sua técnica e seu meio de tratamento, trazendo consigo um marco próprio para suas práticas de cura.

Os benzedores e benzedeiras sempre falarão das enfermidades como fruto advindos destes elementos, entendendo o adoecimento para além das explicações meramente convencionais, mas aliando elementos simbólicos e imaginários passíveis de cura pela reza, pelo mágico e por técnicas de tratamento empregadas por especialistas da medicina popular e da religião, muito embora não sendo reconhecidas pelos órgãos oficiais, mas sim por suas comunidades e pacientes que usufruem das benzeções (LOYOLA,1983). Prossegue a autora:

E o que se pode perceber é que o benzimento, para essas pessoas detentoras de um conhecimento literalmente poderoso, é o ato de tornar benzido ou sagrado algo a ponto de curar. Em outras palavras, o que prevalece é sua função terapêutica aliada à sua função religiosa (LOYOLA, 1983, p. 92).

É no uso das palavras ditas pelos benzedores durante os benzimentos que percebemos a manifestação do "segredo", é ali, junto a uma gama de técnicas ou sinais que vem até serem relatados, que eles acontecem. As palavras que somente eles detêm e somente eles ouvem, e que é característico somente daqueles que possuem o dom e o exerce como ofício para benzer e curar. É perceptível, ainda, que a reprodução de determinadas frases pode ser estimada como uma forma de manutenção da memória, característica de sociedades que se baseiam na oralidade.

Os estudos realizados sobre o saber dos benzedores do município de Tracuateua vêm auxiliar sobre a importância de valorizar e contribuir com os estudos epistemológicos, expandindo e favorecendo a epistemologia do conhecimento e da natureza.

Morin (2011) afirma que deve haver um diálogo entre a ciência e os saberes populares para que possa existir uma facilidade maior do indivíduo em se contextualizar, e que a construção do conhecimento deve considerar a interdependência de outros saberes, desconsiderando se é mais ou menos importante, mas que todo tipo de conhecimento deve estar presente dentro de um todo complexo. Nas palavras do autor:

Complexus significa o que foi tecido junto; há complexidade quando elementos diferentes são inseparáveis constitutivos do todo (como o econômico, político, o sociológico, o psicológico, o afetivo, o mitológico), há um tecido interdependente, interativo e interretroativo entre o objeto de conhecimento e seu contexto, as partes e o todo, o todo e as partes, as partes entre si (MORIN, 2011, p.38).

Conforme o autor entende-se que deva haver uma conexão entre conhecimentos, onde o saber científico possa reconhecer que o benzimento não é uma crendice, mas sim um saber único, um conhecimento como outros que utilizam o sagrado, as orações, as plantas, e energias, transmitindo a cura na vida daqueles que acreditam e dos que não acreditam no benzimento, contribuindo de forma acentuada para somar aprofundamento teórico sobre os elementos simbólicos e religiosos que seguem resistindo, através de seus saberes e domínios cheios de conhecimento popular.

Sinaliza-se, assim, a necessidade de diálogos entre os conhecimentos científicos e populares, apresentando assim um desafio entre aqueles que acreditam que todos os objetos e sujeitos, interagem entre si. Trata-se, por conseguinte de enraizar-se e corroborar o conhecimento dessas pessoas. Clarificar, não somente no meio acadêmico, mas na sociedade, a autoridade e precisão do ofício dos benzedores, no auxílio e nos processos de cura da população. 


\section{CONSIDERAÇÕES FINAIS}

Os estudos realizados entre as benzedeiras e os benzedores do município de Tracuateua são necessários para o conhecimento sobre o ofício dos benzedores e sobre a importância de valorizar e contribuir com os estudos e pesquisas na área da Antropologia da Saúde e em perspectivas interdisciplinares, expandindo e favorecendo a epistemologia do conhecimento e da natureza.

Os registros, os relatos dos benzedores e dos pacientes que praticam e recebem o benzimento, demonstram experiências significativas sobre outra forma de conhecer e estar no mundo, como também as habilidades que vão experimentando ao longo da vida, que são fundamentais para os contextos sociais para que se possa conhecer e compreender como esses saberes estão relacionados à prática do benzimento.

Espera-se que este estudo venha a viabilizar outras pesquisas, partindo de uma análise epistemológica dos benzedores, com registros e problematizações sobre o ofício de benzer e suas práticas de cura.

Acredito que deva ocorrer um diálogo entre a ciência e essas outras formas de conhecimentos para que possa haver um entendimento maior para que o sujeito o entenda, e que a construção do conhecimento deve considerar a interdisciplinaridade e o diálogo entre outros saberes, não considerando se é mais ou menos relevantes e sim diferentes, e essa diversidade contribui para o avanço de um conhecimento compartilhado e não fragmentado.

Entende-se que seja necessário haver uma conexão entre conhecimentos, onde o saber científico possa reconhecer que o benzimento não é uma "crendice", mas sim um saber diferenciado, um conhecimento como outros que utilizam o sagrado, as orações e as plantas transmitindo transformações na vida daqueles que procuram alternativas ou elementos complementares na busca para a cura ou um infortúnio, contribuindo de forma acentuada para somar aprofundamento teórico sobre os elementos simbólicos e religiosos, mas também formas de habilidades que seguem resistindo, através de seus saberes e domínios diversificados de conhecimentos.

É importante reforçar a necessidade de diálogos entre os conhecimentos científicos e outras formas de saber, apresentando assim um desafio entre aqueles que têm uma percepção do ambiente em que todos os objetos, materiais e sujeitos, interagem entre si e produzem assim uma materialidade religiosa. Trata-se, por conseguinte de enraizar-se e corroborar o conhecimento dessas pessoas. Clarificar, não somente no meio acadêmico, mas na sociedade, a autoridade e precisão do ofício dos benzedores, no auxílio e nos processos de cura da população.

Dialogar sobre os saberes de benzedores(as) e as consequências dessa apreensão de conhecimento ou reconhecimento e de suas afinidades com o conhecimento científico, terá reflexos diretos na implantação de políticas públicas que poderão contribuir significativamente para a valorização e interação entre conhecimentos.

Deste modo, o conhecimento pode ser compartilhado e assim, não somente as pessoas que são tratadas pelos benzedores poderão vislumbrar de um saber relevante e que precisa ser estudado, enquanto muitos na sociedade e na academia ainda desconhecem ou sequer reconhecem o caráter epistemológico do ofício dos benzedores no tratamento de doenças.

Estudos realizados sobre o conhecimento das benzedoras e dos benzedores do município de Tracuateua podem contribuir para a possibilidade de valorizar as práticas de benzeção favorecendo a epistemologia da natureza.

Os registros, os relatos dos benzedores e dos pacientes que praticam e recebem o benzimento, demonstram experiências significativas sobre o saber chamado de "popular", que são fundamentais para os contextos sociais para que se possa conhecer e compreender como esses saberes estão relacionados à prática do benzimento. 
Espera-se que este estudo venha viabilizar outras pesquisas, partindo de uma análise epistemológica dos benzedores, com registros e problematizações sobre o ofício de benzer e suas práticas de cura.

\section{REFERÊNCIAS}

ANDRÉ, Marli Elisa Dalmazo A. de. Etnografia da Prática Escolar. 14. ed. Campinas: Papirus, 1997.

ANZAI, Leni Caseli. Vida cotidiana na zona rural do município de Goiás 1888-1930. Goiânia, 1985. Dissertação - Faculdade de Ciências Humanas e Filosofia, Universidade Federal de Goiás. Goiânia, ago. 1985.

CHARTIER, Roger. O mundo como representação. Estudos Avançados, São Paulo, v.5, n.11, p. 173-191, 1991. Trad. Andréa Daher e Zenir Campos Reis. Disponível em: https://www.scielo.br/scielo.php?script=sci_arttext\&pid=S0103-40141991000100010\&ln. Acesso em: 06 ago. 2020.

CONFORTIN, Helena. Benzeduras, superstições, simpatias... Mitos ou realidade. Erechim: EdiFAPES, 2005.

GOMES, Núbia Pereira de Magalhães; PEREIRA, Edimilson de Almeida. Assim se benze em Minas Gerais. Juiz de Fora: EDUFJ/Mazza Edições, 1989.

GOMES, Núbia Pereira de Magalhães; PEREIRA, Edimilson de Almeida. Assim se benze em Minas Gerais: um estudo sobre a cura através da palavra. Belo Horizonte: Mazza Edições, 2004.

INSTITUTO BRASILEIRO DE GEOGRAFIA E ESTATÍSTICA. Tracuateua/PA. [2019]. Disponível em https:cidades.ibge.gov.br/brasil/pa/tracuateua/panorama. Acesso em: 06 ago. 2020.

INGOLD, Timothy. Antropologia: Para que serve? Trad. Beatriz Silveira Castro. Filgueiras. Petrópolis: Vozes, 2019.

INGOLD, Timothy. Da transmissão de representações à educação da atenção. Educação, Porto Alegre, v. 33, n. 1, p. 6-25, jan./abr. 2010. Disponível em: https://revistaseletronicas.pucrs.br/ojs/index.php/faced/article/view/6777/4943. Acesso em: 06 ago. 2020.

INGOLD, Timothy. Estar Vivo: Ensaios sobre Movimento, Conhecimento e Descrição. Trad. Fábio Creder. Petrópolis: Vozes, 2015.

INGOLD , Timothy; ALMEIDA, Rafael Antunes (Trad.). (2018). Antropologia versus etnografia. Cadernos De Campo, São Paulo, v. 1, n. 26, p. 222-228, 2017. Disponível em: https://www.revistas.usp.br/cadernosdecampo/article/view/140192. Acesso em: 06 ago. 2020.

LOYOLA, Maria Andréa. Médicos e curandeiros: conflito social e saúde. São Paulo: Fidel, 1983. 
MACIEL, Marcia Regina Antunes; GUARIM NETO, Germano. Um olhar sobre as benzedeiras de Juruena (Mato Grosso, Brasil) e as plantas usadas para benzer e curar. Boletim do Museu Paraense Emílio Goeldi Ciências Humanas, Belém, v. 1, n. 3, p. 61-77, 2006. Disponível em: https://www.scielo.br/pdf/bgoeldi/v1n3/v1n3a03.pdf. Acesso em: 07 ago. 2020.

MALINOWSKI, Bronislaw C. Argonautas do Pacífico Ocidental: um relato do empreendimento e da aventura dos nativos nos arquipélagos da Nova Guiné melanésia. Trad. Anton P. Carr e Lígia Aparecida Cardieri Mendonça. São Paulo: Abril Cultural, 1978.

MAUÉS, Raymundo Heraldo. A ilha encantada: medicina e xamanismo numa comunidade de pescadores. Belém: Edufpa, 1990.

MAUÉS, Raymundo Heraldo. Catolicismo e pajelanca entre pescadores da zona do Salgado. Comunicações do ISER, Rio de Janeiro, v. 4, n.2, p. 54-61, 1985.

MAUÉS, Raymundo Heraldo. Medicinas populares e pajelança cabocla na Amazônia. In: ALVES, Paulo César; MINAYO, Maria Cecília de Souza (Org.). Saúde e doença: um olhar antropológico. Rio de Janeiro: FIOCRUZ, 1994, p. 73-81. Disponível em:

http://books.scielo.org/id/tdj4g. Acesso em: 07 ago. 2020.

MAUÉS, Raymundo Heraldo. Padres, Pajés, Santos e Festas: catolicismo popular e controle eclesiástico. Belém: CEJUP, 1995.

MORIN, Edgar. Os sete saberes necessários à educação do futuro. Trad. Catarina Eleonora F. da Silva e Jeanne Sawaya; revisão técnica de Edgard de Assis Carvalho. 2. ed. São Paulo: Cortez, Brasília, DF: UNESCO, 2011.

MORIN, Edgar. Introdução ao pensamento complexo. 3. ed. Porto Alegre: Sulina, 2007.

MOTTA-MAUÉS, Maria Angelica; VILLACORTA, Gisela Macambira. Matintapereras e pajés: gênero, corpo e cura na pajelança amazônica (Itapuá/PA). In: ENCONTRO ANUAL DA ANPOCS, n. XXIV, Belém, 2000. Anais [...]. GT11 - Pessoa, Corpo e Doença - Sessão 3, Doença, Gênero e Diferença Social. Belém, 2000. Disponível em: http:bibliotecavirtual.clacso.org.ar/ar/libros/anpocs00/gt11/00gt1132.doc. Acesso em: 07 ago. 2020 .

NASCIMENTO, Danielle Gomes. Tradições Discursivas Orais: Mudanças e Permanências nas Rezas de Cura e Benzeduras Populares da Região de Itabaiana. 2010. Dissertação (Mestrado em Linguística) - Programa de Pós-Graduação em Linguística, Universidade Federal da Paraíba, João Pessoa, 2010.

OLIVEIRA, Elda Rizzo de. O que é benzeção. São Paulo: Editora Brasiliense, 1985a.

OLIVEIRA, Elda Rizzo de. O que é medicina popular. São Paulo: Editora Brasiliense, 1985b.

OLIVEIRA, Oséias de; PADILHA, Milene A. História, Memória e Benzimentos. In: CONGRESSO INTERNACIONAL DE HISTÓRIA, n. V, 21-23 set. 2011, Maringá. Anais 
[...]. Maringá: Universidade Estadual de Maringá, 2011. Disponível em:

http:www.cih.uem.br/anais/2011/trabalhos/279.pdf. Acesso em: 07 ago. 2020.

PARÁ. Secretaria de Estado do Turismo. Inventário da Oferta Turística de Tracuateua.

Belém: SETUR/PA, 2014.

PEINADO, Jurandir; GRAEML, Alexandre Reis. Administração da produção: operações industriais e de serviços. Curitiba: UnicenP, 2007. Disponível em:

http:paginapessoal.utfpr.edu.br/jurandirpeinado/livro-administracao-da-producao/livroadministracao-da-producao/livro2folhas.pdf/at_download/file. Acesso em: 07 ago. 2020.

QUINTANA, Alberto Manuel. A ciência da benzedura: mau-olhado, simpatias e uma pitada de psicanálise. Bauru: EDUSC, 1999.

REIS, Maria Helena de Aviz dos. VIEIRA, Norma Cristina. "Batida" pra elas, cachaça pra eles: o ritual de beberagem na festa de todos os santos na comunidade quilombola de Jurussaca em Tracuateua/PA. Nova Revista Amazônica, Bragança, v. 4, n. 2, 2016. Disponível em: https:periodicos.ufpa.br/index.php/nra/issue/view/332/showToc. Data de acesso: 07 ago. 2020.

SANTOS, Boaventura de Sousa. Para uma Sociologia das Ausências e uma Sociologia das Emergências. In: SANTOS, Boaventura de Sousa (Org.). Conhecimento prudente para uma vida decente: um discurso sobre as ciências revisitado. São Paulo: Cortez, 2004. p. 777-821.

VALE, Giovanna Luiza Santos. A Epistemologia das garrafadas. In: ENCONTRO DE ANTROPOLOGIA VISUAL DA AMÉRICA AMAZÔNICA, n. III, Belém, 19 e 21 de setembro de 2018. Anais [...]. Belém: Universidade Federal do Pará, 2018. Disponível em: http:www.eavaam.com.br/anais/anais/2018/gt11/58.pdf. Acesso em: 07 ago. 2020. 